\title{
Does Vitamin D Improve Osteoarthritis of the Knee: A Randomized Controlled Pilot Trial
}

\author{
Divya Sanghi PhD, Abhishek Mishra MSc, Amar Chandra Sharma MSc, \\ Ajai Singh MS, S. M. Natu PhD, Sarita Agarwal PhD, Rajeshwar Nath Srivastava MS
}

Received: 22 August 2013/Accepted: 22 August 2013/Published online: 11 September 2013

(C) The Association of Bone and Joint Surgeons \& 2013

\section{To the editor,}

We are thankful to Jiang and colleagues for their critical appraisal of our paper. This pilot study fulfills a range of important functions, and can provide valuable insights for other researchers. There is a need for more discussion amongst researchers of both the process and outcomes of such studies.

I agree that we should have mentioned in our conclusion that this study showed the beneficial role of vitamin D in patients with knee osteoarthritis, especially

(Re: Sanghi D, Mishra A, Sharma AC, Singh A, Natu SM, Agarwal S, Srivastava RN. Does Vitamin D Improve Osteoarthritis of the Knee: A Randomized Controlled Pilot Trial [published online ahead of print Aug. 1, 2013]. Clin Orthop Relat Res. Doi: 10.1007/s11999-0133201-6.)

The authors certify that they, or any members of their immediate families, have no funding or commercial associations (eg, consultancies, stock ownership, equity interest, patent/licensing

arrangements, etc.) that might pose a conflict of interest in connection with the submitted article.

All ICMJE Conflict of Interest Forms for authors and Clinical Orthopaedics and Related Research ${ }^{\mathbb{R}}$ editors and board members are on file with the publication and can be viewed on request.

The opinions expressed are those of the writers, and do not reflect the opinion or policy of $C O R R^{\circledR}$ or the Association of Bone and Joint Surgeons ${ }^{\circledR}$.

D. Sanghi, A. Mishra, A. C. Sharma, A. Singh,

R. N. Srivastava $(\square)$

Department of Orthopaedic Surgery, King George's Medical University, Nabiullah Road, near Daliganj Chauraha, Lucknow, India

e-mail: drrnsrivastava@yahoo.com

\section{S. M. Natu}

Department of Pathology, KG Medical University, Lucknow, India those with insufficient vitamin D. Whether vitamin D is effective for all knee osteoarthritis patients requires more randomized controlled trials with on a broader patient population than we included. We also believe that longer followup time would have been helpful. We mentioned in the limitations section of the paper that because we conducted a pilot study, we followed the patients only for 1 year. Importantly, both groups in this study were comparable in terms of demographics, clinical, radiological, and biochemical parameters. We do have the data related to race and occupation, which was again comparable in both the groups, but the data were not presented in the table.

We agree with the statement that different grades of knee osteoarthritis may have different outcomes, but we felt the analysis categorized by knee osteoarthritis grade (Kellgren-Lawrence Grade) was not required, because both the cases and controls were radiographically equivalent at baseline. Therefore, we focused our study on other important endpoints - pain, stiffness, and biochemical changes. Additionally, for the grade-wise analysis, the small sample size and short followup would not have given meaningful results. As for safety monitoring, with the given high prevalence of vitamin D

\footnotetext{
S. Agarwal

Department of Medical Genetics, Sanjay Gandhi Postgraduate

Institute of Medical Sciences (SGPGIMS), Lucknow, India
} 
insufficiency in our population $[1,2]$, and the dosages we used, we did not find any case of hypervitaminosis, symptomatically or on vitamin $\mathrm{D}$ evaluation in regular followups.

As Jiang and colleagues explained, the factors responsible for variance in McAlindon and colleagues' [3] conclusions and our study's conclusions related to clinical efficacy of vitamin D in knee osteoarthritis. The ongoing studies on clinical efficacy of vitamin D in knee osteoarthritis may provide evidence for these unanswered questions in the future.

\section{References}

1. Harinarayan CV, Joshi SR. Vitamin D status in India - its implications and remedial measures. $J$ Assoc Physicians India. 2009;57:40-48.

2. Marwaha RK, Sripathy G. Vitamin D and none mineral density of healthy school children in northern India. Indian J Med Res. 2008;127:239-244.

3. McAlindon T, LaValley M, Schneider E, Nuite M, Lee JY, Price LL, Lo G, Dawson-Hughes B. Effect of vitamin D supplementation on progression of knee pain and cartilage volume loss in patients with symptomatic osteoarthritis: a randomized controlled trial. JAMA. 2013;309:155-162. 